\title{
Classes sociais em Marx e no marxismo, UMA APROXIMAÇÃO
}

\author{
Social classes in Marx and marxism, an approach
}

Clases sociales en Marx y en el marxismo, una aproximación

RESUMO O objetivo deste artigo é debater a definição de classe social, em especial a de classe trabalhadora, a partir da obra de Karl Marx e de outros autores marxistas. O debate sobre o conceito de classe retomou importância no último quarto do século $X X$, diante das transformações no mundo do trabalho ocorridas naquele período. Além dessas transformações, concorre para a indefinição acerca do tema a inexistência na obra de Marx de uma definição fechada de classe social. Em obras diversas, o autor indica diferentes fatores para a definição de classe, o que buscamos resgatar neste artigo. Uma definição de classe que dê conta das novas expressões desse fenômeno é fundamental para que possamos pensar as organizações da classe trabalhadora, bem como, o processo de tomada de consciência.

PalaVRas-chave: Classe trabalhadora. ReEStruturação PRODUTIVA. CLASSES SOCIAIS. CONSCIÊNCIA DE CLASSE.

ABStract The main goal of this work is to discuss the definition of social class, especially working class, from Karl Marx's work and other marxist authors. The debate on the concept of class returned to importance in the last quarter of the 2oth century, in view of the changes in the world of work that occurred in that period. Besides these transformations, it contributes to the indefinition about the theme, the lack in Marx's work of a clear definition of social class. In different works, the author indicates different factors for the definition of class, which we seek to rescue in this article. A class definition that accounts for the new expressions of this phenomenon is fundamental for us to think about the organizations of the working class, as well, as the process of awareness. KEYWORdS: WORKING CLASS. PRODUCTIVE RESTRUCTURING. SOCIAL CLASS. CLASS CONSCIOUSNESS.

RESUMEN El objetivo de este artículo es debatir la definición de clase social, en especial la clase trabajadora, a partir de la obra de Karl Marx y de otros autores marxistas. El debate sobre el concepto de clase retomó importancia en el último cuarto del siglo $\mathrm{XX}$, ante las transformaciones en el mundo del trabajo ocurridas en aquel período. Además de estas transformaciones, concurre a

\section{Estevan Martins de Campos Universidade de São Paulo- USP \\ Marcos Cassin Universidade de São Paulo - USP}

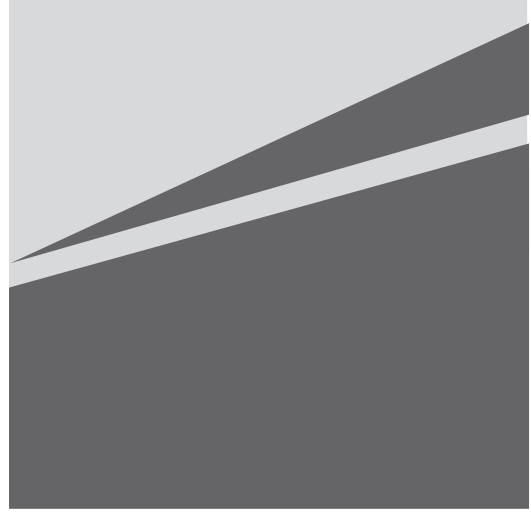


la indefinición acerca del tema la inexistencia en la obra de Marx de una definición cerrada de clase social. En diferentes obras el autor indica diferentes factores para la definición de clase, lo que buscamos rescatar en este artículo. Una definición de clase que dé cuenta de las nuevas expresiones de este fenómeno es fundamental para pensar las organizaciones de la clase obrera, así como el proceso de toma de conciencia.

Palabras Clave: Clase trabajadora. ReESTRUtURACION PRODUCTIVA. CLASES SOCIALES. CONSCIENCIA DE CLASE.

\section{INTRODUÇÃo}

D esde o surgimento e consolidação do capitalismo como forma hegemônica de sociabilidade, nos séculos XVIII e $\mathrm{XIX}$, até os dias de hoje, o mundo do trabalho e as formas de produzir passaram por inúmeras transformações. Transformações essas impulsionadas tanto pelo avanço tecnológico quanto por inovações nas formas de gestão e organização do trabalho.

A formação do capitalismo se deu a partir da separação do trabalhador dos meios de trabalho, naquilo que Marx chamou de acumulação primitiva. Esse processo está na raiz da formação da classe trabalhadora moderna, dissociada dos meios de produção, a quem só resta vender sua força de trabalho.

O processo que cria o sistema capitalista consiste apenas no processo que retira ao trabalhador a propriedade de seus meios de trabalho, um processo que transforma em capital os meios sociais de subsistência e os de produção e converte em assalariados os produtores diretos. A chamada acumulação primitiva é apenas o processo histórico que dissocia o trabalhador dos meios de produção (MARX, 2006, p. 828).

Naquele período, bem como, na primeira metade do século $X X$, quando o desenvolvimento da indústria alcançou o conjunto do globo, a existência da classe trabalhadora não era objeto de questionamento. No entanto, no último quarto do século XX, com a combinação do avanço tecnológico, com a incorporação da microeletrônica ao processo produtivo, entre outras transformações, naquilo que chamamos de reestruturação produtiva, ${ }^{1}$ o debate sobre a centralidade do trabalho, acerca da existência da classe trabalhadora como fenômeno central para a compreensão da sociedade contemporânea, começou a ser questionado. ${ }^{2}$

Parte dos questionamentos a respeito da preservação da centralidade da classe trabalhadora para a compreensão da sociedade contemporânea se dá pelo fato de que, mesmo entre autores marxistas, não há uma formulação consensual do conceito de classes sociais. Portanto, o debate a respeito do conceito de classe na perspectiva do materialismo-histórico é relevante para a compreensão do ser em si da classe, e para que possamos, a partir dessa delimitação, avançar para o estudo das formas de consciência da classe trabalhadora e para a sua tomada de consciência de classe.

É importante, ainda, ressaltar as escolhas dos autores citados. Para a compreensão do fenômeno classe social, nos reportamos aos fundadores do materialismo histórico, Karl Marx e Friedrich Engels, além de

O fenômeno da reestruturação produtiva é um conjunto de transformações tanto na esfera política, com desregulamentação das legislações trabalhistas, abertura comercial, na esfera econômica com a financeirização da economia, mundialização dos processos produtivos, quanto no mundo do trabalho, com transformações no processo produtivo, tanto pela incorporação de tecnologia quanto com novas formas de organização do trabalho. Não é objetivo deste artigo debater tal tema, um estudo aprofundando pode ser encontrado em David Harvey (2005) e Ricardo Antunes (1999; 2005).

2 O debate acerca da centralidade do trabalho e, como consequência, da classe trabalhadora, é encontrado em Antunes (2005). 
utilizarmos autores que incorporaram à teoria marxista novos fenômenos e expressões de classe, como o surgimento da aristocracia operária (LENIN; LUKÁCS) e fenômenos contemporâneos da reconfiguração da classe trabalhadora (ANTUNES; OLIVEIRA). Esperamos que o artigo contribua para delimitar esses critérios para a definição do que é classe social na perspectiva do materialismo histórico.

\section{O SER EM SI DA CLASSE TRABALHADORA}

Pensamos ser necessário iniciar afirmando alguns pressupostos teórico-metodológicos. Partimos do pressuposto que a contradição fundamental da sociedade capitalista é a oposição entre capital e trabalho, uma oposição entre classes antagônicas com interesses opostos e irreconciliáveis, impelidas à luta em defesa de seus interesses, luta essa que está na base das transformações históricas.

Além disso, cabe justificar o motivo de escolha de um ponto de vista de uma classe e isso tem, centralmente, dois motivos. Em primeiro lugar, e mais importante, a identificação com o movimento histórico de emancipação da classe, que teve, ao longo da História, nas mais diversas áreas do conhecimento, intelectuais e acadêmicos realizando pesquisas comprometidas com essa perspectiva emancipatória, sem que esse compromisso implicasse prejuízo do ponto de vista do rigor metodológico.

Em segundo lugar, porque a perspectiva de classe da burguesia representa um limite para a compreensão dos fenômenos sociais à medida que seu interesse de classe, de justificação e de manutenção da atual forma de organização social, impõe-se como barreira para a "possibilidade de dominar intelectualmente a sociedade como totalidade" (LUKÁCS, 2003, p. 259). Lukács foi um dos autores que melhor analisaram as implicações filosóficas da perspectiva de classe da burguesia, em seu História e consciência de classe. Aqui, nos permitimos uma citação mais longa, porém fundamental para compreender tais implicações:
Essa filosofia crítica significa - em muitos aspectos - uma crítica histórica. Ela dissolve sobretudo o caráter fixo, natural e não realizado das formações sociais; ela as desvela como surgidas historicamente e, como tal, submetidas ao devir histórico em todos os aspectos, portanto, como formações predeterminadas ao declínio histórico. Por conseguinte, a história não ocorre somente dentro do domínio de validade dessas formas, segundo o qual a história significaria apenas a mudança de conteúdos, de homens, de situações etc., como princípios sociais eternamente válidos. Essas formas são ainda o objetivo ao qual aspira toda a história e, depois de realizadas, a história chegaria a um fim, pois já teria cumprido sua missão. [...]

O pensamento burguês, contudo, deve deparar aqui com uma barreira intransponível, visto que seu ponto de partida e sua meta são, embora nem sempre consciente, a apologia da ordem existente das coisas ou, pelo menos, a demonstração de sua imutabilidade. "Assim, houve uma história, mas não há mais”, diz Marx a respeito da economia burguesa. Tal frase vale, porém, para toda tentativa do pensamento burguês de dominar o processo histórico pelo pensamento (LUKÁCS, 2003, p. 135-6. (Itálicos do autor da citação, negritos do autor do artigo).

Portanto, o ponto de vista da classe trabalhadora, além de vinculado ao sujeito histórico de transformação da sociedade capitalista, nos permite um estudo com maior possibilidade de aproximação da totalidade.

Mas o que são as classes sociais? O que define uma classe? O que caracteriza o proletariado moderno? Diante de tantas mudanças nas formas de produção, podemos ainda falar 
no proletariado como sujeito da superação da sociedade capitalista? O conceito de luta de classes não está ultrapassado?

Todos esses questionamentos são fundamentais para que possamos compreender o fenômeno da classe na atualidade. É evidente que a classe trabalhadora, os processos de produção e reprodução passaram por enormes transformações nos últimos 200 anos.

Desde que o capitalismo surgiu e se consolidou como forma hegemônica de sociabilidade e reprodução social, com o surgimento do proletariado como classe fundamental, o mundo e o capitalismo se transformaram profundamente. As imagens da classe trabalhadora inglesa do início do século XIX, descritas tanto por Marx quanto por Engels, nos remetem a uma classe trabalhadora muito diversa da que verificamos hoje.

Essas transformações da classe trabaIhadora levam a questionamentos como os já apontados. Com relativa ironia, Daniel Bensaid afirma que "pergunta-se frequentemente hoje em dia se o proletariado estaria ou não em vias de desaparecer [...] Porém, ninguém pergunta se a burguesia desapareceu" (BENSAID, 2013, p. 44).

Porém, quando buscamos afirmar a existência do proletariado e o seu papel como sujeito central da emancipação humana, nos deparamos com uma nova dificuldade: o que define a classe trabalhadora?

Não é incomum a busca por uma definição fechada e precisa do que é classe social, em especial quando tratamos da classe trabalhadora. Ainda que não seja incomum, a utilização do critério "posição que ocupa na estrutura social de produção" (LENIN, 1985, p. 319, grifo do autor) apesar de atender a essa busca de um conceito fechado e definitivo de classe, na nossa compreensão, pode incorrer em uma simplificação que limita a capacidade de entender o fenômeno das classes e suas transformações, sobretudo da classe trabaIhadora. Esse critério tanto não é incomum que o próprio Lukács afirma que "no espírito do marxismo, a divisão da sociedade em classes deve ser determinada segundo a posição no processo de produção" (LUKÁCS, 2003, p. 133).

Por fazer referência ao processo produtivo, tal definição pode, inclusive, reforçar a ideia de que a classe trabalhadora está em vias de desaparecer, uma vez que houve um deslocamento da classe trabalhadora, ao longo do último século, da esfera da produção de mercadorias para a esfera da circulação e prestação de serviços (grifo do autor).

Marx e Engels 3 apresentam, ao longo de sua produção teórica, vários aspectos que ajudam a pensar o fenômeno das classes sociais, sem chegar, no entanto, a uma definição "fechada e definitiva". A principal obra de Marx na maturidade é interrompida exatamente no capítulo em que trataria das classes sociais e de sua definição.

Isso não significa, no entanto, que não possamos, a partir da obra de ambos, nos aproximarmos de uma definição do que é classe social e, especificamente, o que é a classe trabalhadora, o proletariado.

O proletariado aparece nas primeiras obras de Marx em sua Crítica da filosofia do direito de Hegel, quando o autor aponta que “o proletariado está apenas começando a se formar, como resultado do movimento industrial" (MARX, 2005, p. 156), ou seja, coloca o proletariado como produto do desenvolvimento histórico. Esse é o primeiro elemento importante. Engels, em A situação da classe trabalhadora na Inglaterra, também aponta no mesmo sentido, "os primeiros proletários surgiram com a indústria, foram seu produto imediato" (ENGELS, 2010, p. 63). As classes sociais são, portanto, produto do desenvolvimento histórico, e o proletariado surge com o desenvolvimento da indústria e do capitalismo. Esse primeiro aspecto é importante, pois

\footnotetext{
Tomamos como ponto de partida as obras dos fundadores do materialismo histórico-dialético, pois o debate sobre o conceito de classe não é central na produção teórica da primeira metade do século XX, mesmo na obra de Lukács, que tratou das formas de consciência. O debate acerca da centralidade do trabalho e da classe trabalhadora retoma sua importância no último quarto do século, a partir dos estudos a respeito da reestruturação produtiva, sobretudo na Sociologia do Trabalho.
} 
por ser um produto do desenvolvimento histórico, as classes não são naturais nem eternas (negritos do autor do artigo).

Outro aspecto da definição de classes na teoria de Marx e Engels é que as classes se constituem uma em oposição à outra (a burguesia e o proletariado).

Ao mencionar aqui a burguesia, nela incluo também a chamada aristocracia, porque esta aparece como tal, detentora de privilégios, em face da burguesia, não em face do proletariado - nos representantes dessas duas categorias, aristocracia e burguesia, o proletariado vê apenas o proprietário (isto é, o burguês): perante o privilégio da propriedade, todos os outros privilégios desaparecem. A diferença é que o verdadeiro burguês se contrapõe ao proletariado industrial e, em parte, ao proletariado mineiro e, como arrendatário de terras, ao jornaleiro agrícola, ao passo que o aristocrata se relaciona somente com uma parte do proletariado mineiro e com os proletários do campo (ENGELS, 2010, p. 307, grifos do autor do artigo).

Em sua definição de burguesia, Engels inclui também a aristocracia, pois essa se relaciona com setores do proletariado, bem como o "verdadeiro burguês" que "se contrapõe" aos mais diversos setores do proletariado, ou seja, pela função que cumpre na organização social e na oposição concreta do cotidiano, na oposição prática imposta pela defesa de interesses irreconciliáveis, que se constituem (burguesia e proletariado) e se reconhecem a si e aos opositores enquanto representantes de classes distintas.

A propriedade dos meios de produção é outro elemento apresentado para a divisão das classes. A propriedade aparece como critério para a definição de classe nos Manuscritos econômico-filosóficos de 1844, de Karl Marx:
[...] no fim a diferença entre o capitalista e o rentista fundiário desaparece, assim como entre o agricultor e o trabalhador em manufatura, e que, no final das contas, toda a sociedade tem de decompor-se nas duas classes dos proprietários e dos trabalhadores sem propriedade (MARX, 2004 a, p. 79, grifos do citação).

E também na nota de Engels à edição de 1888 do Manifesto do Partido Comunista:

Por burguesia compreende-se a
classe dos capitalistas modernos,
proprietários dos meios de produção
social, que empregam o trabalho
assalariado. Por proletariado, a clas-
se dos assalariados modernos que,
não tendo meios próprios de pro-
dução, são obrigados a vender sua
força de trabalho para sobreviver
(MARX e ENGELS, 2010, p. 40, grifos
do autor do artigo).

Em 18 Brumário de Luís Bonaparte, ao falar do campesinato francês, Marx nos apresenta uma definição de classe não mais a partir de um só critério, mas apontando para uma múltipla determinação, incluindo aí o "modo de vida", os "interesses" e a "cultura".

Milhões de famílias existindo sob as mesmas condições econômicas que separam o seu modo de vida, os seus interesses e a sua cultura do modo de vida, dos interesses e da cultura das demais classes, contrapondo-se a elas como inimigas, formam uma classe. Mas na medida em que existe um vínculo apenas local entre os parceleiros, na medida em que a identidade dos seus interesses não gera entre eles nenhum fator comum, nenhuma união nacional e nenhuma organização política, eles não constituem classe ne- 
nhuma (MARX, 2011, p. 142-3, grifos do autor do artigo).

Além dessa múltipla determinação, Marx coloca, mais uma vez, o fator da luta e da contraposição à outra classe como determinante (não único), chegando a ponto de afirmar, na segunda parte dessa passagem, que no caso dos parceleiros, não havendo "união nacional e nenhuma organização política", eles "não constituem classe nenhuma".

Ainda que Lukács não tenha se ocupado centralmente do debate do conceito de classe, ainda verificamos em suas obras algumas aproximações que apresentam também contribuições para a elucidação do tema. Como a passagem a seguir, em que coloca a separação dos produtores e dos meios de produção, ou seja, a questão da propriedade, como condição do surgimento do capitalismo e, com ele, do "aparecimento do trabalhador livre":

Pois a mecanização racional do processo de trabalho só se torna possível com o aparecimento do 'trabalhador livre', em condições de vender livremente no mercado sua força de trabalho como uma mercadoria 'que Ihe pertence', como uma coisa que 'possui'. [...] A separação do produtor dos seus meios de produção, a dissolução e a desagregação de todas as unidades originais de produção etc., todas as condições econômicas e sociais do nascimento do capitalismo moderno... (LUKÁCS, 2003, p. 207, grifos do autor do artigo).

Apresentamos até aqui uma série de critérios e aspectos da constituição das classes: a classe como produto histórico, a constituição da classe na contraposição à classe opositora, a propriedade (ou não) dos meios de produção e a função na organização social da produção. Sem ainda explicitar uma definição de classe trabalhadora.
Quem melhor sintetizou e correlacionou essas múltiplas determinações da classe social, foi Lênin, em um texto pouco conhecido em que tratava de questões outras do pós revolução de 1917, ele sintetizou da seguinte forma:

Chama-se classes a grandes grupos de pessoas que se diferenciam entre si pelo seu lugar num sistema de produção social historicamente determinado, pela sua relação (as mais das vezes fixada e formulada nas leis) com os meios de produção, pelo seu papel na organização social do trabalho e, consequentemente, pelo modo de obtenção e pelas dimensões da parte da riqueza social de que dispõe. As classes são grupos de pessoas, um dos quais pode apropriar-se do trabalho do outro graças ao fato de ocupar um lugar diferente num regime determinado de economia social (LENIN, 2004, p. 150).

Não é exatamente a definição mais fechada, mas é a definição possível quando se trata de um fenômeno social e histórico como são as classes. Além disso, qualquer que fosse o critério adotado, se único, nos colocaria diante de distorções inevitáveis. Tomemos como exemplo executivos de grandes empresas multinacionais ou de grandes bancos, a rigor, não possuem meios de produção e vendem sua força de trabalho em troca de salário. Se não considerarmos seu "papel na divisão social do trabalho" ou as "dimensões da parte da riqueza social de que dispõe", poderíamos, de maneira equivocada, considerá-los proletários.

Como dissemos no início do artigo, por certo que o mundo do trabalho experimentou diversas transformações nos últimos 100, 200 anos. Qualquer busca nos clássicos por uma definição descritiva, ou que catalogasse profissão por profissão, situação por situação, determinando quem é e quem não é proletário, seria um duplo equívoco. 
Primeiro, do ponto de vista histórico, buscar um "catálogo" de atividades seria equivocado, pois as atividades, profissões, e mesmo posição de determinadas profissões, se alteraram nesse período, profissões desapareceram, outras surgiram. Além de que a mesma profissão pode levar diferentes indivíduos a situações muito distintas (pensemos no caso de artistas, esportistas, profissões em que há altas remunerações e situações de extrema precariedade).

Em segundo lugar, do ponto de vista do método, pois, como afirma Lukács, o materialismo histórico-dialético não significa "um reconhecimento sem crítica dos resultados da investigação de Marx" (LUKÁCS, 2003, p. 64), mas sim a compreensão do método de análise e sua aplicação com rigor.

Nosso entendimento é de reafirmar a divisão da sociedade em classes antagônicas, duas delas as fundamentais, burguesia e proletariado. Mas quem é hoje o proletariado nesse mundo do trabalho complexo e modificado após 200 anos de expansão e consolidação do sistema capitalista em nível mundial?

Ricardo Antunes (2005) procurou atualizar o conceito de proletariado, utilizando o conceito de classe-que-vive-do-trabalho. Alertando para o crescimento da parcela da classe trabalhadora ocupada no setor de serviços (servidores públicos, bancários, comércio), bem como, para o crescimento de formas de subemprego, trabalhadores terceirizados, informais. Buscava com essa atualização da noção de classe, abranger a totalidade dos trabalhadores e trabalhadoras, vendedores da força de trabalho, ainda que mantivesse como núcleo central os trabalhadores produtivos.

Uma noção ampliada de classe trabalhadora inclui, então, todos aqueles e aquelas que vendem sua força de trabalho em troca de salário, incorporando, além do proletariado industrial, dos assalariados do setor de serviços, também o proletariado rural, que vende sua força de trabaIho para o capital (ANTUNES, 1999, p. 102-3).
Todo o amplo leque de assalariados que compreendem o setor de serviços, os trabalhadores 'terceirizados', os trabalhadores do mercado informal, os 'trabalhadores domésticos', os desempregados, os subempregados etc., [...] podem (e devem) somar-se aos trabalhadores diretamente produtivos ${ }^{4}$ e por isso, atuando enquanto classe [...] (ANTUNES, 2005, p. 94).

A dinâmica de acumulação capitalista altera e reconfigura continuamente a organização da produção e da reprodução da vida (e dos lucros). Portanto, qualquer descrição do que e de quem é a classe trabalhadora corre o risco de ficar desatualizada.

Tanto na atualização de Ricardo Antunes quanto na síntese proposta por Lênin, o elemento central para a definição de classe trabalhadora é a venda da força de trabalho, necessária pelo fato de não possuir meios de produção próprios.

\section{Camadas intermediáRias Que OBSCURECEM A LINHA DIVISÓRIA}

Com o desenvolvimento do capitalismo, surgem camadas mais bem remuneradas de assalariados, as quais, hoje, já não podemos denominar proletários, como os "gestores do capital, seus altos funcionários, que detêm papel de controle no processo de trabalho, de valorização e reprodução do capital no interior das empresas e que recebem rendimentos elevados" (ANTUNES, 1999, p. 104).

Essa estratificação dos assalariados com diferentes níveis de remuneração não é exatamente um fenômeno novo. Ainda no início do século XX, Lênin já se referia à formação de uma aristocracia operária, sobretudo nos paí-

4 Existe diferentes utilizações dos termos trabalho produtivo e trabalho improdutivo. Ricardo Antunes emprega, nesse contexto, a expressão para se referir aos trabalhadores que produzem mercadorias. No entanto, Marx (2004 b) faz uma distinção entre trabalho produtivo "em geral" e trabalho produtivo no capitalismo. Ver em especial páginas 117-8. 
ses mais desenvolvidos. Buscava na formação dessa aristocracia operária uma explicação "marxista coerente à eclosão da guerra e especialmente ao colapso simultâneo e traumático da Segunda Internacional" (HOBSBAWN, 2015, p. 163).

Também no início do século XX, Lukács observou o fenômeno da aristocracia operária, apontando para as consequências desse fenômeno sobre as organizações e lutas da classe trabalhadora:

O desenvolvimento capitalista, que inicialmente nivelou e unificou a classe trabalhadora - a qual se encontrava localmente dispersa, distribuída em corporações etc. - cria agora uma nova diferenciação. E esta não tem apenas como consequência o fato de o proletariado deixar de se contrapor à burguesia numa hostilidade unânime. [...] o perigo é que essas camadas, por meio de sua influência nas organizações do proletariado, contribuam para obscurecer a consciência de classe de todos os trabalhadores (LUKÁCS, 2012, p. 48-9).

Com o desenvolvimento do capitalismo essa estratificação dos assalariados tomou novas proporções. Além de uma minoria mais bem remunerada, já observada no início do século XX, surgem novos fenômenos, trabaIhadores assalariados passam a ocupar cargos em conselhos de administração de empresas públicas e privadas, cargos nas administrações de fundos de previdência de empresas públicas, fundos esses que investem em outras empresas (públicas e privadas) e passam a ter interesse nos rendimentos dessas empresas, ainda que isso se dê às custas da saúde e remuneração de outros trabalhadores. Esse fenômeno foi muito bem observado por Francisco de Oliveira em seu Ornitorrinco, que chegou a sugerir que esse setor dos assalariados, com interesses e condições materiais diversos da ampla maioria da classe trabalha- dora, formaria uma nova classe social (OLIVEIRA, 2003, p. 147-9).

Penso não ser o caso de formação de uma "nova classe", mas que os casos citados de assalariados que se tornam gestores e passa a defender o interesse da burguesia se enquadram nos casos de "camadas médias e intermediárias que obscurecem por toda a parte a linha divisória", entre as classes (MARX, 2008, p. 1.163).

Como afirmou Marx no pouco que escreveu no capítulo em que $O$ Capital é interrompido, que trataria exatamente sobre as classes sociais, essas camadas intermediárias não são fundamentais para a análise e compreensão do desenvolvimento histórico:

Sem dúvida, a estrutura econômica da sociedade moderna desenvolveu-se mais ampla e classicamente na Inglaterra. Não obstante, mesmo nesse país não se patenteia pura essa divisão em classes. Também lá, as camadas médias e intermediárias obscurecem por toda a parte as linhas divisórias (embora muito menos nas zonas rurais que nas urbanas). Esse fato, contudo, não tem importância para nossa análise. Vimos ser tendência constante e lei do desenvolvimento do modo capitalista de produção separar cada vez mais do trabalho os meios de produção e concentrar em constelações cada vez maiores os meios de produção dispersos, ou seja, converter o trabalho em trabalho assalariado e os meios de produção em capital (MARX, 2008, p. 1.163, grifos do autor do artigo).

São essas duas classes, burguesia e proletariado, e a luta de classes entre elas fundamentais para compreender e explicar a dinâmica do desenvolvimento histórico sob o capitalismo. Por mais reconfigurada que esteja a classe trabalhadora, não podemos vislumbrar a emancipação humana, no sentido 
de uma sociedade mais livre e plena, sem que as transformações sejam empreendidas por esse sujeito histórico.

\section{ConsideraÇões FINAIS}

O objetivo deste artigo não é esgotar o tema das classes sociais. No entanto, esperamos que os elementos apresentados aqui tenham delimitado uma compreensão do que é, concretamente, a classe trabalhadora em suas múltiplas determinações.

Diante das transformações no mundo do trabalho, dois equívocos devem ser evitados. De um lado, a negação dessas transformações, uma reafirmação das conclusões como se a classe trabalhadora de hoje fosse idêntica à do início do capitalismo. Esse equívoco, ao negar a classe realmente existente, interdita as reflexões sobre o ser da classe e, por conseguinte, o debate acerca de sua organização enquanto sujeito da superação da ordem existente.

De outro lado, a interpretação equivocada das transformações da classe, que colocam a própria existência do proletariado em questão. Que, ao negar a existência do proletariado, impedem a reflexão sobre a natureza das transformações capazes de superar a atual forma de sociabilidade, a saber, o problema da separação dos trabalhadores diretos dos meios de produção.

Ambos os equívocos têm uma raiz comum: a compreensão restrita de classe trabaIhadora exclusivamente como o proletariado fabril, do trabalho somente como trabalho manual, produtor de mercadorias.
Nesse sentido, reafirmamos nosso entendimento de que a definição dada por Lênin, com as múltiplas determinações da classe trabalhadora, nos permite abarcar todas as formas contemporâneas de existência das classes, em especial da classe trabalhadora.

Por fim, é preciso retomar a compreensão de Marx, para quem já no capitalismo do século XIX, na Inglaterra, "não se patenteia pura essa divisão em classes". A existência de inúmeras situações particulares em que a identificação da classe de um indivíduo não seja tão clara não pode servir para invalidar a categoria de classe social. Como afirmou Marx, "camadas médias e intermediárias obscurecem por toda a parte as linhas divisórias" (MARX, 2008, p. 1.163).

Essas camadas médias, casos particulares, não são relevantes do ponto de vista da análise das relações de antagonismo entre as classes fundamentais.

Por fim, uma concepção ampliada da classe trabalhadora, nos moldes de Lênin, nos permite pensar as mais diferentes formas de existência da classe e, a partir destas, pensarmos a questão da consciência de classe e as formas de ação que as organizações dos trabalhadores (movimentos sociais, partidos e sindicatos) devem buscar para atingir a totalidade da classe, na perspectiva do avanço da consciência.

Portanto, o debate sobre classes sociais só pode tomar sentido prático se servir de ponto de partida para o debate acerca da consciência de classe, das práticas educacionais, formais e informais, postas em prática pelas organizações da classe trabalhadora.

\section{REFERÊNCIAS}

ANTUNES, R. Os sentidos do trabalho: ensaio sobre a afirmação e a negação do trabalho, 1. ed. São Paulo: Boitempo Editorial, 1999, 261 p.

. Adeus ao Trabalho? Ensaio sobre as metamorfoses e a centralidade do mundo do trabalho, 10. ed. São Paulo: Cortez; Campinas, SP: Editora da UNICAMP, 2005, 200 p.

BENSAID, D. Marx, manual de instruções, 1. ed. São Paulo: Boitempo Editorial, 2013. 190 p. 
ENGELS, F. A situação da classe trabalhadora na Inglaterra, 1. ed. São Paulo: Boitempo Editorial, 2010, 383 p.

HOBSBAWN, E. J. Revolucionários: ensaios contemporâneos, 5. ed. São Paulo: Paz e Terra, 2015, $361 \mathrm{p}$.

LENIN, V. I. O desenvolvimento do capitalismo na Rússia: o processo de formação do mercado interno para a grande indústria, 2. ed. São Paulo: Nova Cultural, 1985, 402 p.

. Uma grande iniciativa. Obras Escolhidas, v. 3, 2. ed. São Paulo: Alfa-Ômega, 2004, 782 p.

LUKÁCS, G. História e consciência de classe: estudos sobre a dialética marxista, 1. ed. São Paulo: Martins Fontes, 2003, 598 p.

. Lenin: um estudo sobre a unidade de seu pensamento, 1. ed. São Paulo: Boitempo Editorial, 2012, 124 p.

. Reboquismo e dialética: uma resposta aos críticos de 'História e consciência de classe', 1. ed. São Paulo: Boitempo Editorial, 2015, 150 p.

MARX, K. Manuscritos econômico-filosóficos, 1. ed. São Paulo: Boitempo Editorial, 2004 a, 176 p.

. Capítulo VI inédito de 0 capital, resultados do processo de produção imediata, 2. ed. São Paulo: Centauro, 2004 b, 170 p.

. Crítica da filosofia do direito de Hegel, 1. ed. São Paulo: Boitempo Editorial, 2005, 168 p.

. O Capital: crítica da economia política, livro I: o processo de produção do capital, volume II, 21. ed. Rio de Janeiro: Civilização Brasileira, 2006, 966 p.

. O Capital: crítica da economia política, livro terceiro: o processo global de produção capitalista, volume VI, 21. ed. Rio de Janeiro: Civilização Brasileira, 2008, 1.230 p.

. 018 brumário de Luís Bonaparte, 1. ed. São Paulo: Boitempo Editorial, 2011, 174 p.

MARX, K.; ENGELS, F. Manifesto comunista, 1. ed. São Paulo: Boitempo Editorial, 2010, 270 p.

. A ideologia alemã, 1. ed. São Paulo: Boitempo Editorial, 2007, 614 p.

OLIVEIRA, F. Crítica à razão dualista. O ornitorrinco, 1. ed. São Paulo: Boitempo Editorial, 2003, $150 \mathrm{p}$.

Submetido em: 15-5-2018

Aceito em: 31-8-2018 